\title{
A biblioteca fantástica de Mário de Andrade
}

Aline Novais de Almeida ${ }^{1}$

RESUMO: Proponho neste artigo refletir sobre a biblioteca para além de sua vocação documental e de depósito/ acúmulo de saberes, para pensá-la como espaço de escritura, prática relacionada à produção da escrita. Para tanto, relacionarei a biblioteca do escritor Mário de Andrade com a sua obra inacabada, A gramatiquinha da fala brasileira.

PALAVRAS-CHAVE: Mário de Andrade, biblioteca, A gramatiquinha da fala brasileira, poético.

ABSTRACT: In this article I propose a reflection about the library beyond its documental vocation as a deposit and a place for the accumulation of knowledge, thinking about it as a space of writing and as a practice related to the written production. To do so, I intend to link Mário de Andrade’s library with his unfinished work A gramatiquinha da fala brasileira.

KEYWORDS: Mário de Andrade, library, A gramatiquinha da fala brasileira, poetic.

"Para sonhar, não é preciso fechar os olhos, é preciso ler" (FOUCAULT, 2006, p. 80)

\section{A biblioteca fantástica: física e imaginária}

O escritor Mário de Andrade (1893-1945) conseguiu reunir, ao longo de sua vida, uma imensa biblioteca constituída por livros, revistas, jornais, folhetos, separatas e partituras, em diversas línguas e de várias áreas do conhecimento. Os volumes que integram a sua biblioteca particular completam, juntamente com outras coleções de renomados escritores e intelectuais, a biblioteca do patrimônio do Instituto de Estudos Brasileiros da Universidade de São Paulo (IEB - USP) desde 1968.

O processamento deste conjunto mariodeandradiano, realizado pela equipe especializada do IEB, registrou a marca de 17.624 volumes $^{2}$, montante considerável para um sujeito que não dispunha de grandes fontes financeiras, mas que pelo amor inveterado aos livros, passou a colecioná-los e a conservá-los em sua casa ${ }^{3}$.

Como um bom bibliófilo, o escritor modernista investia grande parte da sua renda na coleção de impressos. Comprava títulos em livrarias ou em "fundos de livrarias e editoras falidas" (MORAES, 2010, p. 191-192). Adquiria-os também com "revendedores

l Mestranda em Literatura Brasileira pela Universidade de São Paulo - São Paulo. Bolsista FAPESP. Membro da Equipe Mário de Andrade e do Grupo de Literatura, Loucura e Escritura (GELLE). Contato: alinenovas@gmail.com

2 Dados divulgados por Lanna (2010, p. 197-201). Vale destacar também que na biblioteca do IEB-USP há as coleções de Caio Prado Jr. (1907-1990) com, aproximadamente, 16.000 volumes; José Aderaldo Castello (1921-2011) com 10.687 volumes, José Feliciano de Oliveira, com 7.794 volumes e João Fernando Yan de Almeida Prado, com 10.000 volumes.

3 No Arquivo Mário de Andrade, no IEB-USP, encontra-se as séries I e II Notas de transações com livrarias em nome de Mário de Andrade, as quais focalizam o grande investimento financeiro do escritor em livros e periódicos. Essas séries compreendem os seguintes documentos: notas de créditos, devoluções, faturamentos, notas de compra, notas de entrega e recibos. 
ambulantes que expõem seus livros no chão das ruas" (MORAES, 2010, p. 191-192). Possuía assinatura de periódicos nacionais e internacionais. Em muitas cartas trocadas com seus amigos fazia encomendas, solicitando-lhes exemplares que não encontrou em São Paulo, cidade que, no começo do século XX, apresentava um mercado de livros em crescente desenvolvimento. Sendo um grande apreciador das edições de luxo, não hesitava em obtê-las, estava sempre atualizado em relação aos últimos lançamentos editoriais do Brasil e do exterior. A exemplo disto, pude verificar numa carta de 7 de janeiro de 1925, à amiga Tarsila do Amaral, que na ocasião se encontrava na França, o pedido de compra de livros, em edição de luxo, do poeta Blaise Cendrars com ilustração de Tarsila:

Ontem eu recebi a Nouvelle Revue Française e vi pelos anúncios que o Cendrars vai publicar uma série de livrinhos Notes de Route, impressões da nossa terra, ilustrado por você. Fiquei azoniado com a notícia porque ter esses livrinhos na minha coleção é pra mim um dos maiores desejos deste mundo. Você que foi sempre tão boa pra este seu amigo fiel era capaz de subscrever a coleção toda pra mim? [...]. Se for possível, Tarsila, eu queria a coleção em papel Madagascar, se não mesmo em Holanda serve. Mas veja se me arranja em Madagascar, era uma esmola grande que você fazia pra um amigo que, paciência, tem um fraco pelos livros de luxo. Me arranja, sim? (AMARAL, 2001, p. 91-92)

Mário de Andrade era consulente de bibliotecas públicas e particulares, visitou com frequência a dos amigos Pio Lourenço Corrêa e João Fernando Yan de Almeida Prado. Em contrapartida, muitos amigos usufruíam da sua coleção e, ao emprestar-lhes seus livros, pedia-lhes cuidado. Em carta enviada a Carlos Drummond de Andrade, em 10 de março de 1926, ele demonstrou zelo pelos seus livros:

Só o que peço é que você me mande contar logo se pode mandar registrado aí pra Itabira. Porque também da minha parte não abandonarei o meu egoísmo e os livros caros que você me pedir e que não poderei comprar em dois exemplares e de que terei de emprestar o meu, só mandarei se puderem ir registrados, doutra forma garanto que não mando porque também tenho uma bruta paixão pelos meus livros e serei incapaz de sacrificar os mais queridos mesmo por um amigo. (ANDRADE, 1982, p. 70-71)

A primeira pesquisa acadêmica que se voltou para a biblioteca de Mário de Andrade ocorreu entre os anos de 1963 a 1968. O projeto financiado pela Fundação de Amparo à Pesquisa do Estado de São Paulo (FAPESP) e sob coordenação do Prof. Dr. Antonio Candido de Mello e Souza, da Faculdade de Filosofia, Letras e Ciências Humanas da USP, tinha como objetivo o tombamento do acervo bibliográfico, análise e registro da marginália do escritor. Participaram deste projeto as estudantes Maria Helena Grenbecki, Nites Feres e Telê Ancona Lopez que encaminharam suas dissertações de mestrado no sentido de recolher as leituras, as notas marginais e as ideias que fomentaram o processo criativo de Mário!.

As dissertações de mestrado na área de Teoria Literária e Literatura Comparada da FFLCH-USP das estagiárias participantes do projeto FAPESP, coordenado por Antonio Candido de Mello e Souza são:
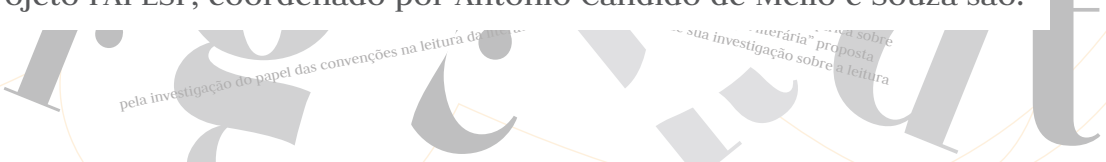
Os volumes de Mário de Andrade estavam distribuídos entre os cômodos de sua casa, localizada na rua Lopes Chaves, 546, no bairro da Barra Funda, em São Paulo. Do hall ao dormitório do escritor era possível encontrar estantes e prateleiras bem cheias. A maior parte dos impressos estava organizada por meio de uma classificação, criada por Mário, que consistia na colagem de etiqueta personalizada na folha de rosto ou anterrosto, com o seu nome impresso e em caixa alta. A etiqueta traz, abaixo do nome do escritor, dois eixos cruzados que definem quatro quadrantes, cada qual com uma informação preenchida manualmente à tinta preta: na parte superior à esquerda a localização do cômodo da casa em letra maiúscula; ao lado em algarismos romanos a estante; abaixo na esquerda a indicação da prateleira em letra minúscula; e no último quadrante em algarismo arábico a obra (LOPEZ, 2002, p. 47). Conforme observa-se na representação abaixo:

\begin{tabular}{l|c}
\multicolumn{2}{c}{ Mário de Andrade } \\
B & I \\
\hline a & 19
\end{tabular}

A respeito desse imenso conjunto de impressos, Telê Ancona Lopez, no prefácio à obra Mário na Lopes Chaves, de Cristiane Yamada Camara, descreve, de forma testemunhal, a disposição não só dos livros, mas do espólio mariodeandradiano que, segundo a pesquisadora, foi mantido pela família do escritor em sua concepção original até a transferência para o IEB-USP em 1968:

No hall, ficavam as vanguardas européias, o modernismo hispano-americano, os nossos poetas do Romantismo e romance do Brasil. Ainda no térreo uma coleção, fantástica para a época, de obras de música, estética e história da arte; na outra sala, geografia, história, os fichários, os discos. No corredor, os contemporâneos brasileiros em duplicata ocupavam a estante baixinha - poesia e ficção. Era assim: no exemplar com dedicatória, a espátula não abria as folhas que, na época vinham ligadas; no segundo, o lápis do leitor corria livre pelas páginas. [...] No porão, muito bem arranjadinhas, as revistas estrangeiras se alinhavam. No primeiro andar, depois do Futebol de Lhote na virada da escada, um outro hall juntava etnografia, folclore do mundo todo, literatura de viagem, pastas com manuscritos de Mário e de outros autores, caixas com fotografias, cartões postais, a famosa correspondência lacrada.[...]

Chegava-se então ao estúdio [...]. Na escrivaninha com estante conjugada assistiam os dicionários; na estante menor, o folclore e os regionalistas do Brasil; [...] Compunham um todo muito bonito, com a mesa redonda, o armário para os santos, de risco inspirado na revista Deutsch Kunst und Dekoration, a cômoda com pastas de desenhos e gravuras [...] a Remington Manuela, o harmônio, Anita, Tarsila, Portinari e Graciano nas

Maria Helena GREMBECKI: “Mario de Andrade e L’Esprit Nouveau” (1968); Nites FERES: "Leituras em francês de Mário de Andrade” (1967) e Telê Ancona LOPEZ: “O se-sequestro da dona ausente: Reconstrução de um estudo de Mário de Andrade a partir de suas notas de leitura” (1967).
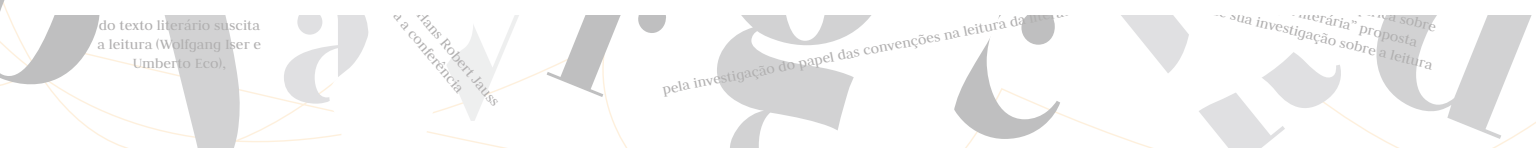
paredes. [...] a estante magra acolhia a paixão do bibliófilo - edições raras e edições de luxo com ilustração de artistas famosos. (LOPEZ, 1996, p. 9-10)

Como bem se pontua na descrição acima, a biblioteca de Mário de Andrade é uma das partes deste rico fundo patrimonial. O seu espólio não se perfaz apenas por impressos, pelo contrário, este é formado também por seu arquivo e por sua coleção de artes visuais. O arquivo contém aproximadamente 30.000 documentos entre manuscritos de suas obras, manuscritos de outros escritores, correspondência (passiva, ativa e de terceiros), fotografias e artigos recortados de periódicos; ademais, a sua discoteca particular, coleção composta por discos nacionais e estrangeiros que estão preservados e digitalizados. A coleção de artes visuais compreende 1.234 peças entre obras de arte, peças de cunho religioso e popular, objetos ligados à Revolução de 1932 e mobiliário (LANNA, 2010, p. 199-201).

Somente reunindo estes três conjuntos - arquivo, biblioteca e coleção de artes visuais - é que podemos ter ideia da totalidade e da amplitude do acervo do escritor. Ele próprio tinha consciência do patrimônio artístico e cultural que havia adquirido ao longo dos anos, compreendendo, inclusive, o valor destes bens quando reunidos.

Em carta à amiga e discípula Oneyda Alvarenga, em 17 de julho de 1940, Mário de Andrade, que na ocasião morava no Rio de Janeiro, orienta a então Diretora da Discoteca Pública Municipal de São Paulo, a receber, com muita cordialidade Carleton Srague Smith, musicólogo norte-americano e Diretor da Seção de Musicologia da Biblioteca Nacional de Nova York, que chegaria a São Paulo nos próximos dias. Além de recebê-lo, era necessário mostrar-lhe a cidade e suas instituições: "tudo que é nosso, Biblioteca, Discoteca, Pesquisas do Sérgio [Milliet], si ele quiser ver os Parques Infantis, Embu [...] e si ele quiser e fizer muita questão, a minha biblioteca particular" (ALVARENGA, 1983, p. 240). Mário adverte Oneyda que apresentar a sua biblioteca ao musicólogo significa mostrá-la "em tudo o que ela é" (1983, p. 240), ou seja, "seus 10 mil volumes, seus milhares de peças musicais, correspondência, manuscritos, obras raras ou de luxo, coleção de desenhos ou gravuras, marfins, peças de coleção etc" (1983, p. 240).

Diante disso, percebe-se que Mário de Andrade tem uma concepção outra de sua própria biblioteca. Ele vincula um sentido alargado ao lugar, o qual congrega não apenas livros, mas outros objetos sentimentais. A biblioteca é para ele um espaço ${ }^{5}$ afetivo, de permanente frequentação que torna possível a prática de sua escritura.

Se para o escritor a biblioteca tinha tal relevância, eram necessários cuidados especiais com aquele espaço. Duas pessoas próximas ajudaram-no a cuidar do seu patrimônio, num primeiro momento, a sua irmã mais nova, Maria de Lourdes, até casar-se; depois José Bento Faria Ferraz, seu aluno do Conservatório Dramático e Musical de São Paulo, que foi contratado como secretário particular. Durante quase 6 anos, José Bento cuidou com muito zelo do arquivo e da biblioteca do escritor, atuando, em alguns momentos, como seu colaborador nas pesquisas que desenvolvia ${ }^{6}$.

Sobre a noção de "espaço escritural”, ver: Galíndez-Jorge (2009).

A respeito da colaboração de José Bento Faria Ferraz, ver: Grillo (2010).

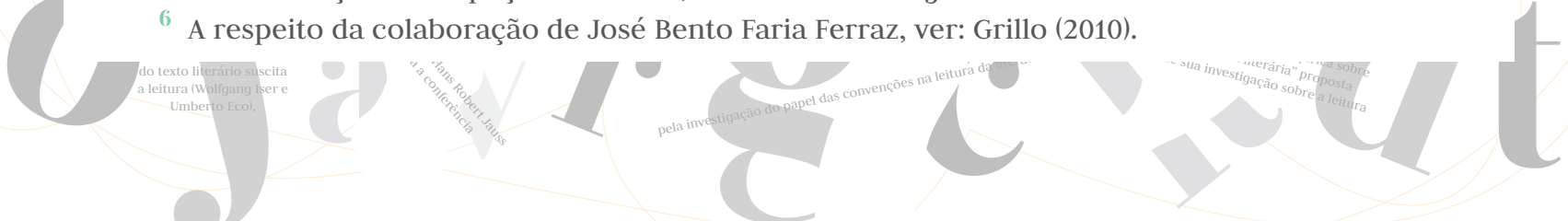


De acordo com a "Cronologia" de Mário de Andrade, presente na edição crítica de Macunaíma de 1996, elaborada por Tatiana Maria Longo Santos e Telê Ancona Lopez, o escritor paulistano começou a formar a sua biblioteca particular em 1910, um ano antes, aos dezesseis, já era bacharel em Ciências e Letras, pelo Ginásio Nossa Senhora do Carmo, dos irmãos maristas, consagrada instituição de origem francesa, provedora de educação católica para a juventude de São Paulo. Nesta época, as instituições educacionais católicas eram espaços que cultivavam importantes bibliotecas; como é o caso do famoso acervo dos monges beneditinos, no Mosteiro de São Bento, que, certamente, o jovem Mário frequentou na sua rápida passagem, em 1910, quando frequentou, na Faculdade de Filosofia, Ciências e Letras São Bento, filiada à Universidade de Louvain na Bélgica, os cursos de Filosofia e Literatura.

No entanto, mesmo antes do contato escolar, pode-se observar a relação de Mário de Andrade com os livros. Seu pai Carlos Augusto de Andrade (1855-1917) foi autodidata e incutiu nos filhos o gosto pela leitura e pelo conhecimento; eles cresceram vendo o pai envolvido na promoção de peças teatrais. Em carta à Oneyda Alvarenga, em 14 de setembro de 1940, Mário de Andrade escreve sobre seu pai: "E como, ainda por cima, estava rodeado de circunstâncias felizes, um pai que sem ser nada rico me dava quanto livro eu pedia (e eu pedia com a maior indiferença pelas dificuldades financeiras dele que eu sabia serem reais) [...]" (ALVARENGA, 1983, p. 275-276).

O patriarca da família Andrade transitou por várias áreas profissionais, atuando como tipógrafo, jornalista, comerciante e contador, contudo se destacou como jornalista, sendo, inclusive, um dos fundadores do primeiro vespertino da cidade de São Paulo, a Folha da tarde, em 1879. Ele integrou também o diário A Constituinte - Orgam Liberal, pertencente a Brasílio Machado e a Joaquim de Almeida Leite de Moraes (1834-1895), tornando este último, anos mais tarde, em 1887, seu genro, ao se casar com Maria Luísa Leite de Moraes.

Em relação ao avô materno de Mário de Andrade, é preciso sublinhar a sua biografia, já que exerceu uma valorosa influência para o neto. Leite de Moraes era de família tradicional e abastada de São Paulo. Foi jornalista e deputado por três vezes à Assembleia Provincial, era advogado e lente da Faculdade de Direito de São Paulo. Em 1881, foi nomeado presidente da Província de Goiás, onde ali exerceu seu mandato entre 1 de fevereiro e 9 de dezembro. Na companhia do futuro genro, seu secretário particular e oficial de gabinete, realizou, em 1882, uma longa viagem pela região goiana, através dos rios Vermelho, Araguaia e Tocantins, chegando até o Pará. Os relatos desta viagem lendária, com muitas aventuras e perigos, ficaram registrados no livro de Leite de $\mathrm{Mo}^{-}$ raes Apontamentos de viagem de São Paulo à capital de Goiás, desta à do Pará, pelos rios Araguaia e Tocantins e do Pará à Corte: considerações administrativas e políticas.

Em seu ensaio "O avô Presidente", Gilda de Mello e Souza, evidencia a importância que o livro do avô representou para Mário de Andrade. Para autora, o livro foi um "dos talismãs" (1982, p. 98) da infância do escritor, além de estabelecer diálogo com o famoso romance-rapsódico do neto, Macunaíma, o herói sem nenhum caráter:

[...] não é descabido afirmar que os Apontamentos em que Joaquim de Almeida Leite de Moraes anotou para seu registro e deleite da família a viagem lendária que realizou pelo
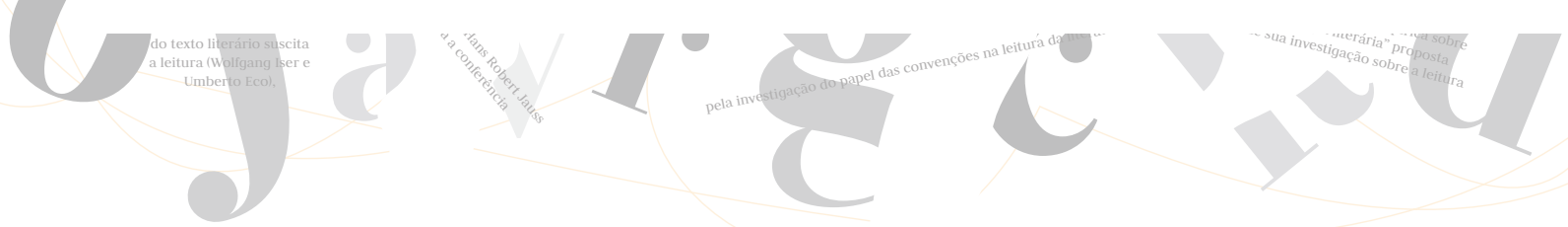
Brasil em 1882, em companhia de seu futuro genro Carlos Augusto de Andrade, constituem um documento importante na formação da sensibilidade de Mário de Andrade. É possível que o livrinho singelo que ele conservou sempre ao alcance da mão tenha sido um dos primeiros incentivos para conhecer o seu país. (MELLO e SOUZA, 1982, p. 102)

Além das figuras do pai e do avô materno, outro familiar muito relevante é o primo Pio Lourenço Corrêa (1875-1957), mais conhecido como tio Pio. Casado com uma de suas primas, tio Pio possuía uma chácara em Araraquara, onde Mário costumava ir para descansar. Estabeleceram uma longa correspondência, pois o fazendeiro lhe despertava muito interesse, era um tipo ilustrado do campo, grande conhecedor da língua portuguesa e amante do tupi. Apreciador da leitura, organizou uma vasta biblioteca, consultada inúmeras vezes pelo escritor. Tio Pio foi um leitor assíduo e severo dos textos do primo e por esta razão protagonizaram discussões acerca linguagem literária empregada pelo modernista. Ainda que houvesse controvérsia entre ambos, Mário estava sempre disposto a ler e a ouvir opinião dele.

O amigo de Mário de Andrade, Rubem Borba de Moraes, no texto de apresentação de seu livro Lembrança de Mário de Andrade 7 cartas salienta o apreço que o escritor modernista tinha pelo fazendeiro Pio Lourenço Corrêa:

Na chácara [Mário de Andrade] passava temporadas ouvindo seu Pio Lourenço contar casos, falar de passarinhos, de árvores, de costumes e superstições dos caboclos. Era uma enciclopédia viva, esse homem adorável. Nunca perdia ocasião de conversar com ele quando o encontrava em Araraquara. É uma pena que não tivesse escrito memórias ou recordações. Nada ficou de tudo quanto sabia como ninguém. Mário, como disse, aproveitou algumas estórias que o tio contava para escrever contos. (MORAES, 1979, p. 7)

Diante da apresentação destas três referências familiares que foram responsáveis, de certa forma, pelo amor à leitura e aos livros, podemos pensá-las, junto com Rubem Borba de Moraes, como enciclopédias vivas por marcarem a filiação de Mário de Andrade com os saberes e a arte. Esta parentela contribuiu para a formação do seu capital cultural, formaram o seu acervo imaginário que é composto por um enorme cabedal que inclui outras enciclopédias vivas, aquilo que foi observado, os sentimentos, a oralidade - desde a fala, os ritmos, os sons da natureza até as canções ouvidas nos discos e pelos cantadores.

Nesse sentido, a noção de biblioteca imaginária consigna leituras de outra ordem, as quais unidas à biblioteca física compõem o repertório de Mário. Isso porque ele sabe que o seu fazer, a sua prática escritural não se pretende inspirada, mas se faz por meio de estudos e de leituras que se consolidam, de forma metódica, em seu Fichário analítico (espécie de enciclopédia pessoal, buscador de assuntos e temas para os seus escritos), nos fichamentos de leituras, nas notas de estudo (notas de trabalho), nos traços e notas marginais deixadas nos seus volumes e, é claro, nos manuscritos. 


\section{A fantástica giramaticuinha da fala brasileira}

Todas as obras de Mário de Andrade constituem-se através de um processo de documentação sistemática. Não lhe carece inspiração, o seu trabalho fundamental é ler, não para acumular e ostentar erudição, mas para implodir aquilo que lê. O escritor, além disso, desloca o tempo todo as leituras realizadas no interesse de encontrar novas possibilidades poéticas. Nessa perspectiva, convém problematizar a relação de sua biblioteca particular com A gramatiquinha da fala brasileira. No manuscrito da obra manifesta-se a construção de uma nova forma poética, aponta-se para uma po- $^{-}$ esia decalcada numa gramática.

A leitura do texto de Michel Foucault "Posfácio a Flaubert (A tentação de Santo Antão)", de 1964, publicado também como "A biblioteca fantástica" (1967), possibilitou-me desenvolver a proposta deste artigo, pois o crítico francês relaciona a prática de escrita de Gustave Flaubert com o espaço de biblioteca. A escritura flaubertiana, ao passar pela biblioteca para se documentar, acaba por desvelar uma potencialidade criativa e imaginativa muito forte.

A documentação levantada por Flaubert está totalmente permeável em seu texto, o que permite ao leitor perceber que a matéria literária utilizada é formada por infinitos textos. É livro feito de livro. Nas palavras de Foucault:

Porque o século XIX descobriu um espaço de imaginação cuja potência as épocas precedentes não haviam sem dúvida pressuposto. Esse novo lugar dos fantasmas não é mais a noite, o sono da razão, o vazio incerto aberto diante do despejo; pelo contrário, é a vigília, a atenção infatigável, o zelo erudito, a atenção às emboscadas [...]; ele [Flaubert] se desdobra cuidadosamente na biblioteca aturdida, com suas colunas de livros, seus títulos alinhados e suas prateleiras que a fecham de todos os lados, mas entreabrem do outro lado para mundos impossíveis. O imaginário se aloja entre o livro e a lâmpada. (FOUCAULT, 2006, p. 79-80)

Cabe ressaltar que, ao analisar A tentação de Santo Antão, Foucault não propõe o retorno aos livros consultados pelo romancista francês na tentativa de se obter o efeito da obra e tampouco da leitura. O que importa é o ato que se instaura no momento da leitura, o toque afetivo que a leitura evoca, como evocou para Flaubert. A leitura é aqui concebida como intervalar (GALÍNDEZ-JORGE, 2009), ou seja, aquela que é desencadeadora de um novo processo criativo que deverá ser feito pelo leitor. Ler no intervalo significa ler sob uma instância problematizadora que leva em questão a minha perspectiva crítica daquilo. É ler no texto, ao mesmo tempo, o que veio antes e o que está por vir.

Através dessa leitura feita no intervalo percebem-se formas de subjetividade que emergem do escrito. Ler não significa acumular saber, mas significa sonhar, penetrar nesse intervalo repleto de sentimentos, de "entre textos", de sujeitos e, é claro, da literatura.

Nesse sentido, o que Foucault aponta a respeito da obra de Gustave Flaubert, vista pelo "fenômeno de biblioteca" (FOUCAULT, 2006, p. 80), vai ao encontro da prática de escrita de Mário de Andrade que também concebe a biblioteca como espaço escritural,
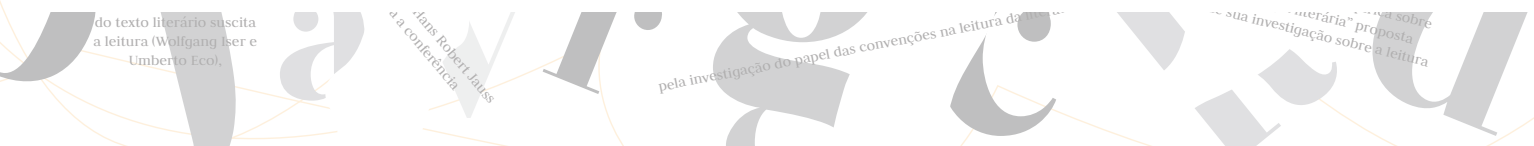
local em que se produz documentos na tentativa de escrever a sua obra. A escritura de ambos apresenta um mecanismo análogo de construção: a leitura.

Nas obras mariodeandradianas, pode-se reconhecer o aludido fenômeno de biblioteca, principalmente, ao se voltar aos seus manuscritos, pois se vislumbram, de forma mais cabal, por meio de sua materialidade, os lastros da sua biblioteca física e imaginária. O escritor tinha por hábito conservar em seu arquivo apenas os manuscritos das obras inacabadas. Dos trabalhos que se formalizaram por meio da publicação, pouco se têm dos vestígios processuais, restam poucas notas de trabalho que foram reaproveitadas em novos projetos ou os "exemplares de trabalho" que dariam origem a novas edições.

Mário de Andrade valorizava os seus trabalhos incompletos - estes foram muito bem ordenados no seu arquivo -, porque reconhece que nesse material há marcas de um processo escritural, no qual esteve implicado o tempo todo, mesmo que não tenha culminado num produto final. Parece-lhe interessar mais o processo do que o resultado, já que no processual manifesta-se uma série de potencialidades da criação, uma série de virtualidades que apontam várias perspectivas para a obra. Enquanto há processo de criação, há embate, tensão e indeterminação.

No caso específico d'A gramatiquinha da fala brasileira - projeto inacabado e inédito de um livro que aborda aspectos linguísticos, psicológicos e poéticos da língua portuguesa falada no Brasil - evidencia-se um conjunto documental muito amplo e rico que performatiza a própria biblioteca pessoal do escritor. O manuscrito da obra prefigura, justamente, esse momento de tensão escritural, haja vista o esforço de Mário em reunir os materiais para sistematizar as suas ideias acerca da fala brasileira. O material foi por mim identificado e analisado em sua natureza, meios de escrita, suporte, conservação e em seu estatuto genético, no interesse de preparar uma edição genética da obra, corpus da minha pesquisa para o mestrado.

A análise documentária e escritural proporcionou-me a ordenação e a montagem do dossiê, o qual é constituído por aproximadamente 270 documentos $^{8}$, totalizando 348 fólios. Compondo o dossiê do manuscrito estão presentes: caderneta, na qual o autor esboça planos, notas de trabalho, prefácio e versão de texto. Há também, fora da caderneta, outras notas de trabalho e versões de texto, cartas, bilhetes, artigos recortados de periódicos, fichas bibliográficas, etiqueta da biblioteca de Mário de Andrade, volante de propaganda do estabelecimento paulistano Dancing Neptuno.

Como já afirmei anteriormente, a noção de biblioteca para Mário é muito alargada, por isso esse conjunto de documentos d'A gramatiquinha, estabelecido pela pesquisa, completa-se com outras séries documentais do escritor: na correspondência ativa e passiva, na discoteca particular, no manuscrito do Fichário analítico, nos recortes de artigos de periódicos. Eventualmente, percebe-se também diálogos com as obras publicadas.

Os exemplares de trabalho de Mário de Andrade são textos impressos (publicados em jornais, revistas ou livros) que apresentam valor de manuscrito por acolher rasuras sobre as quais o autor trabalhou acréscimos, cortes e deslocamentos.

8 Como a pesquisa está em andamento, apresentarei oportunamente a quantidade de documentos que perfaz o dossiê.
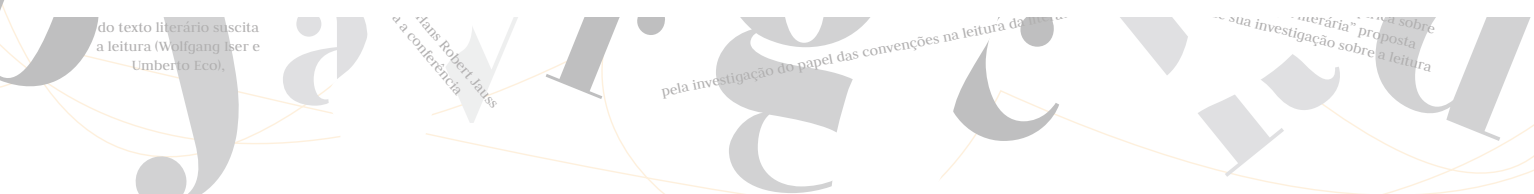
Nota-se, portanto, que a documentação coligida para criação desse audacioso estudo é extremamente heterogênea. Destaca-se, entre o material reunido, uma numerosa quantidade de notas de trabalho que evidenciam leituras não só da área de linguagem, mas de obras literárias, bem como notas colhidas por meio de oitiva, nas pesquisas de campo que realizou pelo Brasil. Vale ressaltar também a presença de um bilhete do poeta Manuel Bandeira a Mário de Andrade, encaminhando uma bibliografia elaborada pelo renomado professor e filólogo Sousa da Silveira, a pedido do próprio Mário que desejava ler "livros sobre língua". . A indicação de Sousa da Silveira é, essencialmente, da área de língua e linguagem, a saber: Le language, de Jules Vendryes; La vie du langage, de Albert Dauzat; Éléments de linguistique romane, de Edouard Eugène Joseph Bourciez; Esquisse d'une dialectologie portugaise, de Leite de Vasconcelos; Histoire de la langue française des origines à 1900, de Ferdinand Brunot; O dialeto caipira, de Amadeu Amaral; O linguajar carioca, de Antenor Nascentes, artigos na Revista de filologia portuguesa, de São Paulo, sob o título "Carta ao exmo. Sr. Dr. Antenor Nascentes", de Jorge Guimarães Daupiás. O único título literário dessa lista se refere a um trecho do posfácio à segunda edição do romance Iracema, de José de Alencar.

As obras sugeridas por Sousa da Silveira foram, possivelmente, lidas por Mário de Andrade - estão na biblioteca do escritor e muitas possuem marcas e anotações (notas marginais); são referenciais teóricos que estão dissolvidos, em grande medida, em notas de trabalho e versões de texto ${ }^{10}$.

Entre os documentos de sua Gramatiquinha, verifica-se, por vezes, alusão a outros sujeitos que participaram, mesmo que de forma indireta, da investigação do escritor, como é o caso de Pio Lourenço Corrêa, que oferece explicações e materiais (cartas, notas de trabalho com referências bibliográficas) para o estudo do primo. Os intelectuais nordestinos Ascenso Ferreira, Luís da Câmara Cascudo e Antonio Bento de Araújo Lima são citados em notas de trabalho do manuscrito, pois em determinadas cartas que enviaram a Mário de Andrade fizeram o uso da fala brasileira, tornando-se informantes da pesquisa do amigo.

Embora esse manuscrito sinalize um trabalho de grande diligência documental, observa-se na versão de texto, para o prefácio da obra, o autor se figurar de modo inseguro em relação ao seu projeto:

Esta é a 1a vez/ em que me sinto verdadeiramen-/te timido ao publicar um livro/e incerto sobre a validade dês-/ te. É certo que estudei até maneira/ o possivel entre os acasos da mi-/nha vida autodidatica a lin/ gua portuguesa de que deriva/ em maior parte a nossa manei-/ra de expressão, porêm é tam-/bem certo que esse conhecimen-/to não é suficiente pra eu me/meter nas altas cavalarias de es-/crever um livro de linguagem. / Me parece francamente que/careci ter topete pra agir assim/ e o meu livro me parece a/ primeira real mas não bem/ clarificada na consciencia ma-/ nifestação de cabotonismo/

9 Em carta a Manuel Bandeira, [anterior a 13 de setembro de 1925], Mário de Andrade exige do amigo a listagem de livros sobre língua que o mesmo lhe prometera: "Não se esqueça que você inda não me mandou o nome dos livros sobre língua que prometeu” (MORAES, 2000, p. 232).

10 A respeito das leituras realizadas por Mário de Andrade para composição d’A gramatiquinha da fala brasileira, ver: Edith Pimentel Pinto (1990).
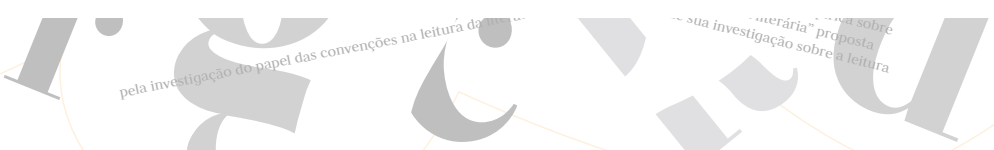
da minha vida artistica. Ou/tros é que deviam escrever este/ livro e tenho consciencia de / que um dia a Livro da Fala/ Gramatica da Fala Brasileira/ será escrito. (ANDRADE, Mário de. A gramatiquinha da fala brasileira. Série Manuscritos Mário de Andrade, IEB-USP) ${ }^{11}$

Parece que a timidez do autor de Macunaíma não decorre da falta de conhecimento sobre a língua portuguesa. Desenham-se, nesse trecho, as indeterminações e os percalços do seu trabalho com a escritura. A pesquisa que ele realizou, a documentação que levantou, transformaram-se em outra coisa. O tom linguístico, a descrição de uma fala/ língua que deveria existir, cede lugar para o poético. Tanto é assim que o autor escreve, primeiramente, o "Livro da Fala", rasura-o e substitui por "Gramatica da Fala Brasileira". E mesmo esta última nomeação é ambígua, já que se esboça a letra "q" ao final da palavra, denotando uma hesitação. Talvez ele pensasse em escrever Gramatiquinha. De todo modo, a impressão que fica é que $A$ gramatiquinha da fala brasileira está locada entre estes dois pontos, não sendo nem um e nem outro.

Seria impossível para Mário construir uma gramática nos moldes tradicionais, já que a sua Gramatiquinha era calcada na apreensão das constâncias da fala, conforme nota de trabalho do manuscrito: "Gramatinha/ Não falar nem uma/ vez em regras. Nem tão/ pouco em normas si/ possivel. Falar só em/ 'Constancias"'. (ANDRADE, Mário de. A gramatiquinha da fala brasileira. Série Manuscritos Mário de Andrade, IEB-USP).

Dessa maneira, A gramatiquinha não ocupa o lugar normativo nem descritivo. Ela está instalada em um campo instável, aquele que é próprio da literatura. Mário de Andrade manipula a noção de gramática não como limite, mas como escritura. Em outras palavras, a gramática aqui assume o lugar de pergunta permanente pela linguagem e ao mesmo tempo a impossibilidade de se chegar à resposta.

Desde a minha primeira leitura do manuscrito, percebo que o autor avança mais para o campo poético do que para o campo prescritivo. O que de certa forma é elucidado pelo deslocar da leitura que o autor experimentou no espaço escritural da sua biblioteca (física e imaginária). Apesar do seu amplo levantamento documental, a capacidade de representabilidade de uma gramática é despontada pela potencialidade poética que tal materialidade vislumbra. Na nota de número 23, presente na caderneta, há uma anotação sobre a não funcionalidade do gênero gramática, mas, em contrapartida, acaba por assentar uma perspectiva lírica à obra:

\footnotetext{
Nem uma só vez dar exem-/ plos vulgares, genero 'Pedro/ matou Paulo'. Todo exemplo/ será reflexão profunda. Será fra-/ se lirica adoravel. Será julga-/ mento critico. Será ataque ou/ sarcasmo. No máximo com brasileirismos/ rarissimo dar exemplo palavra isolada, so quando já contiver lirismo (ANDRADE, Mário de. A gramatiquinha da fala brasileira. Série Manuscritos Mário de Andrade, IEB-USP)
}

Se os exemplos incorporados n’A gramatiquinha não se encerram na instância linguística, mas apontam para o lirismo, para o poético, tais escolhas definem a escritura.

II Foram mantidas em todas as citações d'A gramatiquinha da fala brasileira a escrita original do manuscrito (transcrição diplomática).
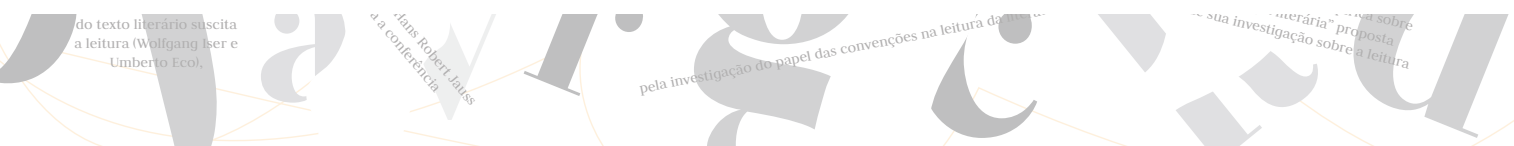
O título da obra, mesmo no diminutivo, instaura a primeira leitura da obra. Como leitores, conhecemos uma gramática, temos referência do que seja o gênero. Contudo, percebemos que a proposta de leitura, o pacto de leitura, não se cumpre. A tentativa de (re)escrever uma gramática é desarticulada e Mário de Andrade escreve, pela ótica do poeta, outra obra que é não passível de determinação.

\section{Referências bibliográficas}

AMARAL, Aracy (org.). Correspondência de Mário de Andrade e Tarsila do Amaral. São Paulo: Edusp/ Instituto de Estudos Brasileiros, 2001.

ALVARENGA, Oneyda (org.). Cartas: Mário de Andrade - Oneyda Alvarenga. São Paulo: Duas Cidades, 1983.

ANDRADE, Carlos Drummond de (org.). Lição de amigo: cartas de Mário de Andrade a Carlos Drummond de Andrade. Rio de Janeiro: Livraria José Olympio, 1982.

ANDRADE, Mário de. A gramatiquinha da fala brasileira. Série Manuscritos Mário de Andrade, IEB-USP.

FOUCAULT, Michel. "La bibliothèque fantastique". In: Cahiers de la compagnie Madeleine Renaud-Jean-Louis Barrault, no 59, mars, 1967.

“Posfácio a Flaubert (A tentação de Santo Antão)". In: Ditos \& escritos III - Estética: Literatura e Pintura, Música e Cinema. Trad. Inês Autran Dourado Barbosa. Rio de Janeiro: Forense Universitária, 2006.

GALÍNDEZ-JORGE, Verónica. Fogos de artifício: Flaubert e a escritura. São Paulo: Ateliê Editorial, 2009.

GRILlO, Angela Teodoro. Processo de criação do estudo Preto, um inédito de Mário de Andrade. Dissertação (Mestrado em Literatura Brasileira) - Faculdade de Filosofia, Letras e Ciências Humanas, Universidade de São Paulo, São Paulo, 2010.

LANNA, Ana Lúcia Duarte (org.). Guia do IEB: o acervo do Instituto de Estudos Brasileiros. São Paulo: Instituto de Estudos Brasileiros, 2010.

LOPEZ, Telê Ancona. "Prefácio... também crônica". In: CAMARA, Cristiane Yamada. Mário na Lopes Chaves. São Paulo: Fundação Memorial da América Latina, 1996.

“A biblioteca de Mário de Andrade: seara e celeiro da criação”. In: ZULAR, Roberto (org.). Criação em processo: ensaios de crítica genética. São Paulo: Iluminuras, 2002.

MELLO e SOUZA, Gilda de. "O avô Presidente". In: Exercícios de leitura. São Paulo: Duas cidades, 1980.

MORAES, Marcos Antonio de (org.). Correspondência Mário de Andrade \& Manuel Bandeira. São Paulo: Edusp/ Instituto de Estudos Brasileiros, 2000.

“Fräulein em processo". In: SAGAWA, Roberto (org.). O amar de Mário de Andrade. Assis: FCL Publicações, 2010.

MORAES, Rubem Borba de. “Amigo”. In: Lembrança de Mário de Andrade 7 cartas. São Paulo: Digital Gráfica, 1979.

PINTO, Edith Pimentel. A gramatiquinha de Mário de Andrade: texto e contexto. São Paulo: Duas Cidades, 1990. 
SANTOS, Tatiana Maria Longo; LOPEZ, Telê Ancona. "Cronologia”. In: Macunaíma, o herói sem nenhum caráter. Edição crítica de Telê Porto Ancona Lopez, coord. 2 ed.. Paris/ Madri/ México/ Buenos Aires/São Paulo/Rio de Janeiro/ Lima: Association Archives de la Littérature latino-américaine, des Caraïbes du XXe siècle/ CNPq, 1996, p. 207-227 (Coleção Archivos).

ArTigo ReCEBIDO EV: 19 ago. 2012

ArTigo ACEITO Ev: 12 set. 2012

REFERÊNCIA ELETRÔNICA: ALMEIDA, Aline Novais de. A biblioteca fantástica de Mário de Andrade. Revista Criação \& Crítica, n. 9, p. 140-151, nov. 2012. Disponível em: <http://www.revistas.usp.br/criacaoecritica>. Acesso em dd mmm aaaa.
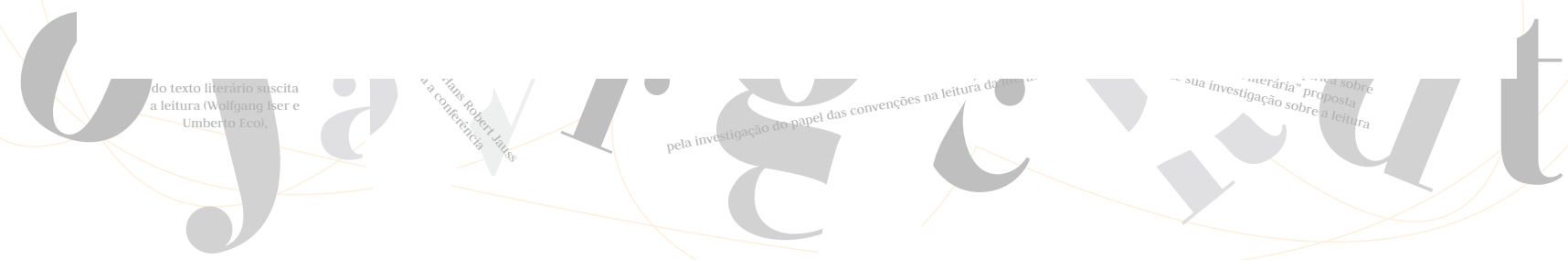